Brit. J. industr. Med., 1961, 18, 283.

\title{
A RAPID METHOD FOR THE MICRO-ESTIMATION OF LEAD IN URINE
}

\author{
BY \\ J. M. DICK, R. W. ELLIS, and J. STEEL \\ From the Nuffield Department of Industrial Health, King's College, Newcastle upon Tyne \\ University of Durham
}

(RECEIVED FOR PUBLICATION JANUARY 2, 1961)

\begin{abstract}
A method is described for the determination of microgram quantities of lead in small volumes of urine. Recoveries from urine samples of added lead show that the mean results of triplicate analyses will, 19 times out of 20 , lie within $\pm 12.5 \mu \mathrm{g}$. per litre of the true concentration. The determination of lead in a single specimen of urine may be carried out in three hours.
\end{abstract}

In the literature on the estimation of urinary lead, it is usually recommended that not less than $100 \mathrm{ml}$. aliquots of the urine sample be taken for analysis. This has certain disadvantages, not the least of which is the time required to ash the organic content of the urine. In addition, spot samples of urine collected from groups of workmen are often less than the $200 \mathrm{ml}$. volume required for duplicate estimations. For these reasons, a rapid and accurate method was sought for the determination of total lead in small volumes of urine. The method finally devised is based on the dithizone mono-colour method described by Fischer and Leopoldi (1940).

The organic matter in a $20 \mathrm{ml}$. sample of urine is destroyed by ashing with nitric acid and the residue is dissolved in water. Bismuth is detected and removed by washing at $p \mathrm{H}$ 3.0-3.4 with a solution of dithizone in chloroform which is then discarded.

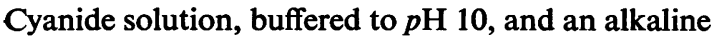
solution of dithizone are added and lead is extracted as the dithizonate into chloroform. Excess dithizone is washed out of the organic phase with potassium cyanide solution. The optical density of the washed chloroform extract is directly proportional to the quantity of lead present.

The advantages claimed for the method are as follows:

1. The small volume of urine needed for an accurate determination considerably reduces the time required to ash the sample and hence the time taken for the determination.

2. The ashing and extraction of lead with dithizone are carried out in the same vessel, thus reducing contamination from external sources.

\section{Apparatus}

The ashing and first extraction are carried out in a $50 \mathrm{ml}$. "Pyrex" glass conical flask fitted with a B19 socket. This flask is fitted with a B19 cone carrying a $2 \mathrm{~mm}$. bore stopcock and $4 \mathrm{~cm}$. stem (Fig. 1).

Excess dithizone is removed in a $150 \mathrm{ml}$. "Pyrex" separating funnel.

In order to render it lead-free, all glassware is treated with hot $50 \%$ nitric acid and rinsed with distilled water followed by lead-free water. The flasks should be kept covered at all times except during acid digestion, or when additions are made. Reagents are stored in "Polythene" wash bottles from which dropwise additions may conveniently be made. Where more accurate additions are required, the reagents are best stored in "Polythene" and borosilicate glass automatic dispensers. Spectrophotometric measurements are carried out on a "Unicam" SP600 spectrophotometer using $2 \mathrm{~cm}$. glass cells.

\section{Reagents}

For details of methods for the preparation of lead-free reagents see the Report of the Analytical Methods Committee (1954).

Lead-free water.-Distilled water re-distilled in an all "Pyrex" glass apparatus.

Nitric Acid $0.5 N$. -Dilute $31 \mathrm{ml}$. concentrated nitric acid (B.D.H., low in lead) to 1 litre with lead-free water.

Hydrochloric Acid 1N.-Dilute $86 \mathrm{ml}$. concentrated hydrochloric acid (B.D.H., low in lead) to 1 litre with lead-free water.

Ammonium Hydroxide 5N.-Dilute $355 \mathrm{ml}$. concentrated 0.880 ammonium hydroxide (B.D.H., low in lead) to 1 litre with lead-free water. 


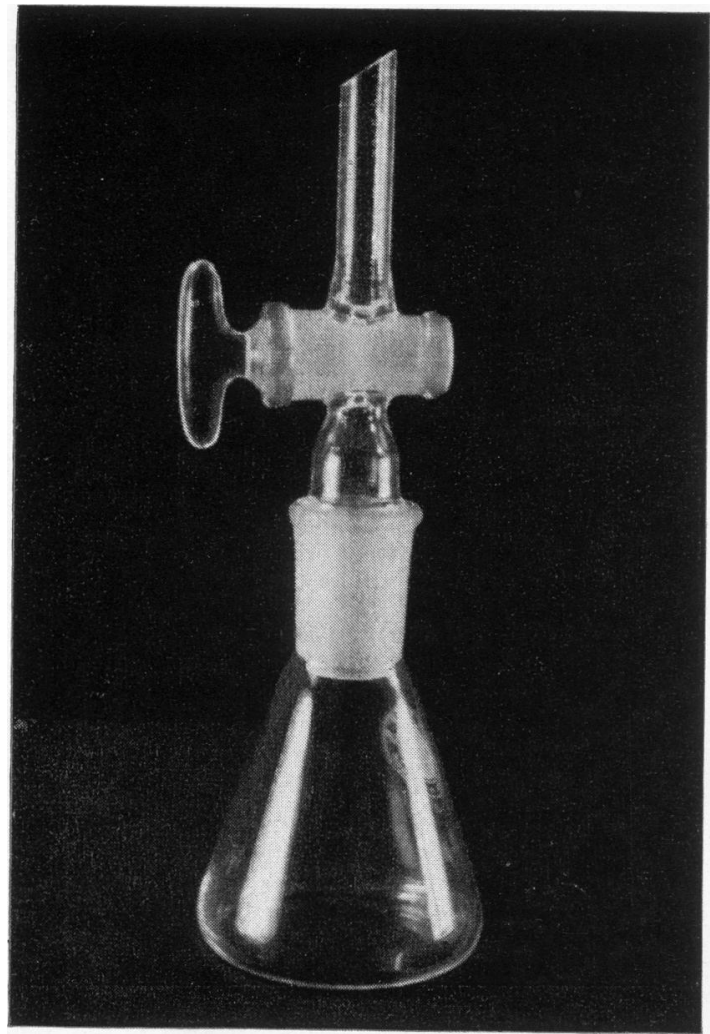

FIG. 1.-The ashing and extraction flask.

Chloroform.-Laboratory reagent chloroform stabilized by the addition of about $1 \%$ by weight of ethyl alcohol.

Dithizone Solution A.-Make up fresh each day. Dissolve $0.02 \mathrm{~g}$. of pure diphenylthiocarbazone in $40 \mathrm{ml}$. of chloroform. To this solution add $4 \mathrm{ml}$. of $5 \mathrm{~N}$ ammonium hydroxide, $36 \mathrm{ml}$. lead-free water, and shake for 30 seconds. Allow the phases to separate and reject the chloroform layer. The aqueous layer is dithizone solution A.

Dithizone Solution B.-Take $30 \mathrm{ml}$. of dithizone solution $A$ and acidify with $1 \mathrm{~N}$ hydrochloric acid until a permanent precipitate just forms. Add $20 \mathrm{ml}$. chloroform and shake for 30 seconds. Allow the phases to separate and reject the aqueous layer. The chloroform layer is dithizone solution B.

Ammonium Citrate Solution.-Dissolve 400 g. citric acid crystals in water and add sufficient reagent ammonia to make the solution alkaline to phenol red. Dilute the solution to 1 litre with water and make lead-free.

Potassium Cyanide $10 \% \mathrm{~W} / \mathrm{V}$ Solution.-Dissolve $50 \mathrm{~g}$. of potassium cyanide in sufficient water to make $100 \mathrm{ml}$., remove the lead content, and dilute the concentrated solution to $500 \mathrm{ml}$. with lead-free water.
Ammonium Citrate/Potassium Cyanide Solution.-Mix five parts of ammonium citrate solution with two parts of potassium cyanide solution. This solution is freshly prepared each day.

Methyl Orange Indicator Solution.- $0.1 \%$ solution in lead-free water.

Phenolphthalein.-Dissolve $1 \mathrm{~g}$. of phenolphthalein in $50 \mathrm{ml}$. of alcohol and add $50 \mathrm{ml}$. of lead-free water.

Antifoam.-Midland Silicone Antifoam "A"; 2\% solution in carbon tetrachloride.

Standard Lead Solutions.-Dissolve $1.5984 \mathrm{~g}$. of dried recrystallized lead nitrate in 1 litre of $1 \%$ nitric acid $(10 \mathrm{ml}$. of nitric acid diluted to 1 litre with lead-free water).

One millilitre $=1.0 \mathrm{mg}$. $\mathrm{Pb}$.

This solution keeps indefinitely in "Pyrex" glass or "Polythene" flasks.

Prepare a standard solution contining $1 \mu \mathrm{g} . \mathrm{Pb}$ per $\mathrm{ml}$. by dilution of stock solution with $1 \%$ nitric acid. This dilute solution should be prepared as required.

\section{Method}

Acid Digestion.-Measure $20 \mathrm{ml}$. of urine into the 50 ml. flask, add two drops of Antifoam "A" and $1 \mathrm{ml}$. of concentrated nitric acid. If the urine collection contains a phosphate or carbonate deposit, add concentrated nitric acid (exactly $5 \%$ of the total urine volume), shake until the urine is clear, and withdraw $21 \mathrm{ml}$. aliquots for analysis. Insert the stopcock with the tap in the open position, and take the contents of the flask to dryness on the hot plate. Remove the flask from the hot plate in order to prevent ignition of the residue which will almost certainly produce a low result. Add 10 drops of nitric acid to the residue and again take to dryness. Repeat the operation once more so that a pure white residue is obtained. Dissolve the residue in 10 drops of acid and $10 \mathrm{ml}$. of lead-free water, bring the solution to the boil and allow to cool.

The solution should now be clear but occasionally it may be clouded due to the presence of silica which, however, does not interfere with the determination of lead.

Determination of Lead.-Add one drop of methyl orange indicator to the clear solution followed by sufficient $5 \mathrm{~N}$ ammonia solution to produce a yellow colour. Adjust the $p \mathrm{H}$ of the solution to $3 \cdot 0-3.4$ by the addition of $0.5 \mathrm{~N}$ nitric acid until a peach pink colour is produced. Add five drops of dithizone solution B and $5 \mathrm{ml}$. of chloroform. Shake the flask for 30 seconds, invert, and allow the contents to settle. The colour of the chloroform layer should be green showing excess dithizone, but if it is orange indicating the presence of bismuth, then add more dithizone solution $B$ and repeat the process until the chloroform layer is coloured green. Discard the chloroform layer: this operation may be facilitated by warming the base of the flask with the hand.

Add three drops of phenolphthalein indicator to the solution followed by $1.4 \mathrm{ml}$. of ammonium citrate/ potassium cyanide solution. Add $5 \mathrm{~N}$ ammonium hydroxide until the $p \mathrm{H}$ of the solution reaches 10.0 as shown by the red colour of the indicator. Measure 
carefully $10 \mathrm{ml}$. of chloroform into the flask followed by one drop of dithizone solution A. Shake the flask for 30 seconds and allow the layers to separate. If the chloroform layer is cherry red add another drop of dithizone solution $\mathrm{A}$, shake the flask for 30 seconds, and again observe the colour of the chloroform layer. Repeat the addition of dithizone solution A until the colour of the chloroform layer is mauve, blue, or green showing the presence of excess dithizone.

Run the chloroform layer into a $150 \mathrm{ml}$. separating funnel containing $50 \mathrm{ml}$. of $0.5 \%$ potassium cyanide solution $(2.5 \mathrm{ml}$. of $10 \%$ potassium cyanide solution made up to $50 \mathrm{ml}$. with lead-free water) and shake for 30 seconds. Dry the stem of the funnel with a rolled filter paper and plug lightly with cotton wool. Discard the first few drops of the chloroform layer and run the remainder of the layer into a $2 \mathrm{~cm}$. spectrophotometer cell.

Measure the optical density of the chloroform solution at $520 \mathrm{~m} \mu$ using chloroform as the reference solution. Carry out a blank determination with each series of tests.

Standard Curve.-Transfer aliquots of standard solution containing $0,1,2,3,4$, and 5 micrograms of lead to $50 \mathrm{ml}$. conical flasks and make up the volumes to $20 \mathrm{ml}$. with lead-free water. Treat the solutions in

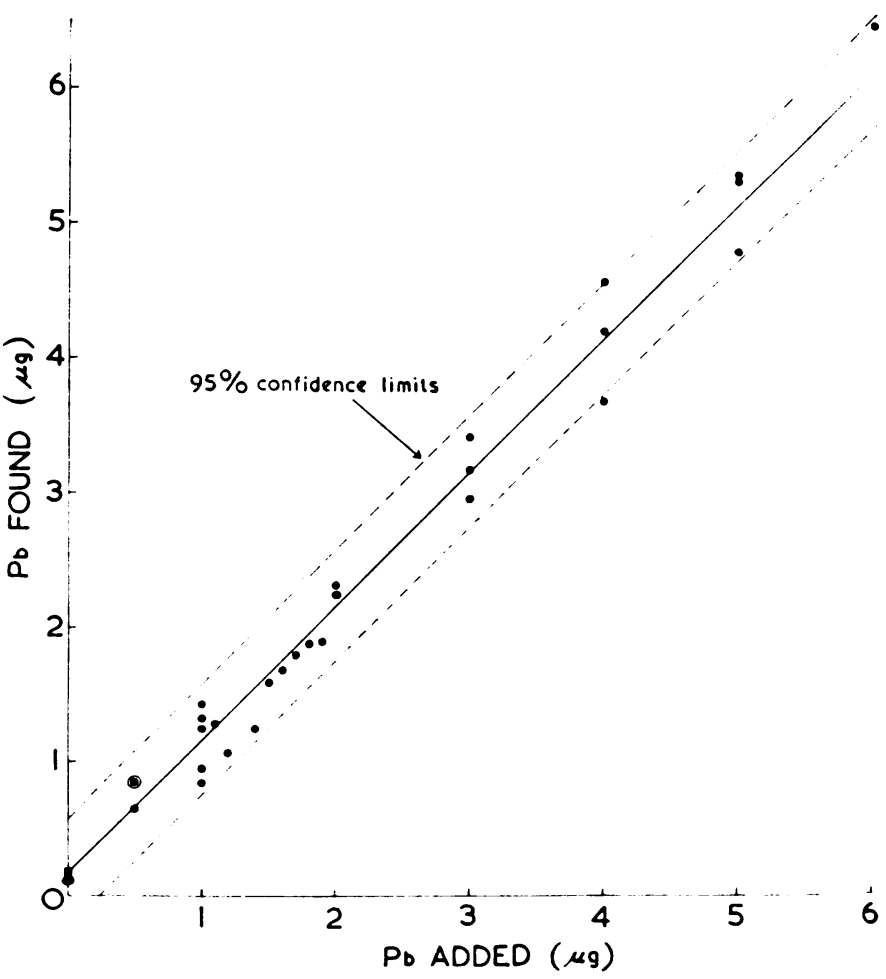

FIG. 2.-Recovery of lead added to urine samples.

Confidence limits calculated for single, the mean of duplicate, and the mean of triplicate estimations show that $95 \%$ of results will fall within the range of $\pm 21 \cdot 7, \pm 15 \cdot 3$, and $\pm 12.5 \mu \mathrm{g}$. per litre, respectively, of the true concentration of urinary lead. The mean value of triplicate analyses is thus considered to be sufficiently precise for the method to be used as an aid in the diagnosis of lead absorption or intoxication.

\section{Discussion}

Stannous tin, bismuth, and thallium, as well as lead, are extracted from alkaline cyanide solution by dithizone. Although these metals are infrequently present in urine, the following precautions were taken to prevent interference: (1) the nitric acid digestion converts any stannous tin to the stannic form which, in amounts usually present in urine, does not interfere; (2) bismuth is removed by dithizone extraction at $p \mathrm{H} 3 \cdot 0-3 \cdot 4 ;$ (3) the $0.5 \%$ potassium cyanide solution used to wash the chloroform extract removes any thallium, along with excess dithizone, from the chloroform layer.

In order to standardize the error due to the slight solubility of chloroform in potassium cyanide amounted to $0 \cdot 15 \mu \mathrm{g}$. per $20 \mathrm{ml}$. 
solution, the volume of the cyanide wash was carefully controlled.

Because of the minute amounts of lead involved in the estimation, the elimination of sources of contamination is of the utmost importance. This is largely achieved by the use of plastic "squeeze" wash bottles as reagent dispensers. In this way contamination from pipettes, burette taps, and flask stoppers is avoided. Moreover, a considerable saving in time is effected by the use of dispensers rather than pipettes and this, taken together with the comparatively short time required to ash a $20 \mathrm{ml}$. sample, means that triplicate analyses of a single urine collection may be carried out in about three hours.

Parallel investigations of the mixed colour and reversion methods of lead estimation have shown that, under the conditions described above, the mono-colour method is to be preferred because of its higher sensitivity and lower variability.

The authors are grateful to Mr. D. J. Newell and Mrs. D. Weightman for statistical advice and calculations.

\section{REFERENCES}

Fischer, H., and Leopoldi, G. (1940). Z. anal. Chem., 119, 161. Report of the Analytical Methods Committee (1954).' Analyst, 79, 397. 